\title{
Partial reinforcement effect: The expectancy of reward on nonreward trials*
}

\author{
ROGER L. MELLGREN, JOHN P. LOMBARDO†, DAN M. WRATHER \\ and ROBERT FRANK WEISS \\ University of Oklahoma, Norman, Oklahoma 73069
}

\begin{abstract}
In order to determine the importance of the development of expectancy of reward prior to partial reward trials; rats were given 20 continuously reinforced trials prior to 20 partially reinforced trials (CRF-PRF) and compared to Ss given only 20 partially reinforced trials (PRF). Control groups received 20 or 40 continuously reinforced trials (CRF-20, CRF 40) to determine the effect of differing numbers of acquisition trials. Results showed that terminal acquisition differences were minimal in the run segment of the alley and that Group CRF-PRF was more resistant to extinction than Group PRF, and both were more resistant to extinction than the CRF-20 and CRF-40 groups, which did not differ from each other. These results were interpreted as supporting the notion that the expectancy of reward on nonreward trials during partial reinforcement acquisition is a determiner of the magnitude of the partial reinforcement extinction effect.
\end{abstract}

The frustration explanation of the partial reinforcement extinction effect (PREE) requires that the expectancy of reward $\left(\mathrm{r}_{\mathrm{r}}\right)$ be developed first so that later primary frustration $\left(R_{F}\right)$ will occur on nonreward trials and subsequently the anticipation of frustration $\left(r_{f}\right)$ and its stimulus consequence $\left(s_{\mathrm{f}}\right)$ will be conditioned to approach (Amsel, 1967). If $s_{f}$ has not been conditioned to approach at the start of extinction, then the PREE will not occur.

Capaldi's sequential hypothesis requires only that nonreinforced trials be followed by a reinforced running trial in order to produce a PREE (Capaldi, 1966, 1967). No mention is made of the necessity of establishing an expectancy of reward prior to partial reinforcement in order for PREE to occur, although recently Capaldi and Waters (1970) and Capaldi, Berg, and Sparling (1971) have considered the possible importance of some form of frustration during PRF acquisition in governing resistance to extinction.

Sutherland and Mackintosh (1971) claim that continuous reinforcement (establishing $r_{r}$ ) prior to partial reinforcement training will reduce the PREE relative to a condition where only partial reinforcement training is given. This prediction is based on the notion that a determiner of the PREE is the number of stimulus analyzers which are switched in and that continuous reinforcement will strengthen only one analyzer and produce less resistance to extinction because only responses to this analyzer need to be weakened for

\footnotetext{
*Supported in part by funds provided by the Faculty Research Committee, University of Oklahoma. Reprint requests should be addressed to Roger L. Mellgren, Department of Psychology, University of Oklahoma, Norman, Oklahoma 73069.

$\dagger$ Now at State University of New York at Cortland.
}

extinction to take place. Sutherland, Mackintosh, and Wolfe (1965) have presented data which they claim support their prediction, but this experiment is subject to criticism for a number of reasons. First, their partially reinforced groups were much inferior to continuously reinforced groups at the end of acquisition. This result, especially after the extended training they used, is simply not in agreement with other findings (see Brown \& Farber, 1968). Second, no correction for differing acquisition levels was made in comparing extinction performance. Finally, the use of trials to extinction criterion is somewhat unusual and may have different properties than running speeds in extinction.

The experiment presented here was an attempt to determine the importance of the development of the expectancy of reward prior to partial reward trials. Two groups received 20 trials of partial reward on exactly the same schedule, but one group had 20 continuously rewarded trials prior to partial reward (CRF-PRF), while the other group had only the partial reward trials (PRF). In order to control for number of trials, one control group received 20 continuously reinforced trials (CRF-20) and a second control group received 40 continuously reinforced trials (CRF-40). Previous experience with the apparatus and background parameters suggested that 20 trials would be sufficient for the Ss to approach asymptote, allowing evaluation of extinction differences uncontaminated by different terminal acquisition levels. Frustration theory predicts that resistance to extinction for the CRF.PRF condition should be greater than the PRF condition. The nonfrustrative version of the sequential hypothesis predicts no difference between the PRF and CRF-PRF groups, but both should be superior to the control groups. A version of sequential theory with frustrative components (e.g.. Capaldi \& Waters, 1970; Capaldi et al, 


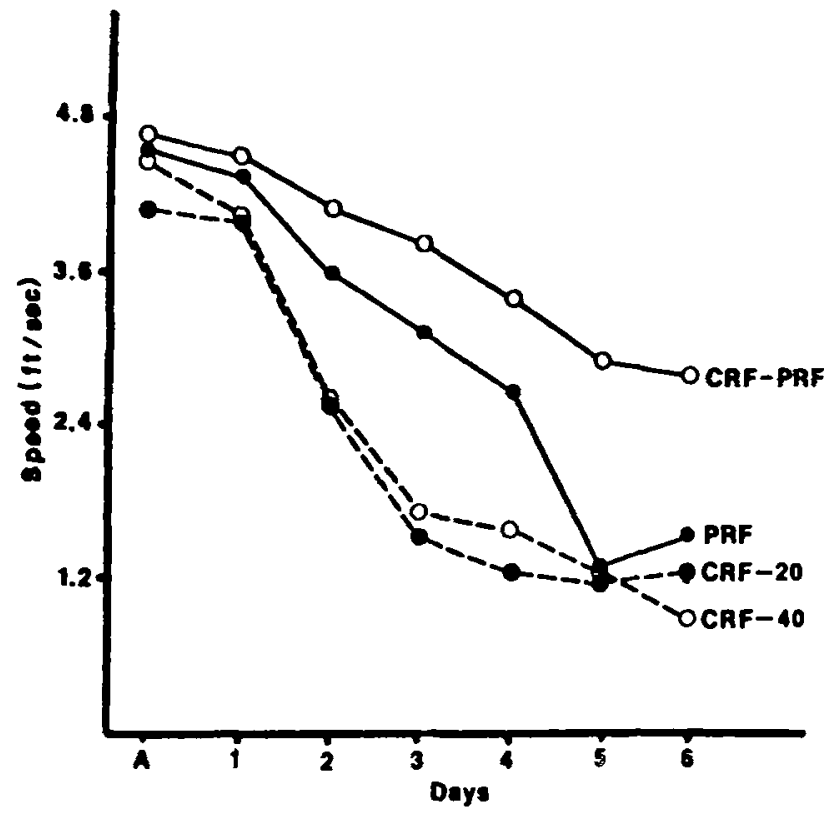

Fig. 1. Mean total speeds for the four groups on the last day of acquisition (Point " $A$ ") and the 6 days of extinction.

1971) makes the same prediction as frustration theory. Finally, stimulus analyzer theory (Sutherland \& Mackintosh, 1971) predicts that Group PRF should be more resistant to extinction than Group CRF.PRF.

\section{METHOD}

\section{Subjects}

A total of 48 male albino rats were obtained from the Holtzman Co., Madison, Wisconsin, and were randomly distributed into four equal-sized groups.

\section{Apparatus}

A black wooden runway was used and was divided into separate segments by guillotine doors. The startbox was $30.4 \mathrm{~cm}$ long, the run section was $114.3 \mathrm{~cm}$ long, and the goalbox was $38.4 \mathrm{~cm}$ long. All parts of the apparatus were $15.2 \mathrm{~cm}$ side and $17.7 \mathrm{~cm}$ high and were covered by a hinged hardware cloth top. A teaspoon was mounted in the middle of the back wall of the goalbox, $5.6 \mathrm{~cm}$ up from the floor, and served as a foodcup.

Start, run, and goal times were recorded to the nearest $1 / 100 \mathrm{sec}$ by means of Standard timers operated by a microswitch on the startbox door and a series of three photoelectric cells. The first photocell was located $15.24 \mathrm{~cm}$ beyond the startbox door and stopped the clock which was started when the startbox door was raised (start time). A second photocell was located $8.8 \mathrm{~cm}$ in front of the goalbox door and stopped the clock which was started when the first photocell was broken (run time). The third photocell was $11.5 \mathrm{~cm}$ inside the goalbox and stopped the clock which started when the second photocell was broken (goal time).

\section{Procedure}

Upon arriving in the laboratory, the Ss were housed two in a cage and allowed ad lib food and water for 3 days. A $23 \frac{1}{2}-\mathrm{h}$ feeding schedule was then established for 8 days. Ad lib access to water was maintained throughout the experiment, but only $1 / 2-h$ periods of access to Purina Lab Chow after each experimental session were allowed. On the last 2 days of the preexperimental period, all Ss were marked for identification and allowed to eat a number of 45-mg Noyes food pellets in their home cages. The Ss were also handled for periods of 3-5 min each day for the last 4 days preceding the start of the experiment.

The general procedure used was to place the $S$ in the startbox from the individual carrying cage and wait $3 \mathrm{sec}$ before opening the startbox door. After the $S$ left the startbox, the door was closed behind it and the $S$ was allowed to traverse the runway to the goalbox. When the $S$ entered the goalbox, the goalbox door was lowered to prevent retracing.

Two groups of Ss were given four trials of CRF for 5 days. One of these groups continued for 5 more days on the CRF schedule (Group CRF 40), and the other was continued on a $50 \%$ PRF schedule for 5 days (Group CRF-PRF). Two other groups were simply maintained on the $231 / 2-h$ food-deprivation schedule for the first 5 days. On the next 5 days, one group of Ss was given 20 CRF trials (Group CRF-20) and the second group was given 20 PRF (50\%) trials (Group PRF). The schedule of PRF was identical for Groups CRF-PRF and PRF. Reward on all trials consisted of four 45 -mg Noyes food pellets, and nonreward resulted in goalbox confinement for a period of $15 \mathrm{sec}$. The Ss were run in squads of four (one from each condition), with an intertrial interval of 3-5 min.

All Ss were given 6 days of extinction immediately following acquisition, four trials per day. The procedure used in acquisition was the same as in extinction, except the foodcup was empty.

All times (start, run, goal, total) were converted to speeds $(\mathrm{ft} / \mathrm{sec})$ for all analyses.

\section{RESULTS}

\section{Terminal Acquisition}

Differences in speeds in terminal acquisition were highly dependent on the runway segment. Analyses of variance for the last acquisition day revealed that the PRF-CRF and PRF groups were superior to the CRF-20 and CRF 40 groups in start speeds (a main effect of schedule, $F=7.54$, df $=1 / 44, p<.01$ ), but trials and the interaction of Schedule by Trials were not significant ( $F=0.7$ and $1.36, \mathrm{df}=1 / 44$, respectively). The run speed analysis revealed no significant difference due to trials $(\mathrm{F}=3.02, \mathrm{df}=1 / 44, \mathrm{p}>.05)$. Both schedule and the Schedule by Trials interaction were also nonsignificant ( $F=.78$ and $.59, \mathrm{df}=1 / 44$, respectively). The goal speed analysis revealed a significant effect due to trials $(F=4.33$, df $=1 / 44, p<.05)$, with the Ss receiving 40 trials being superior in this measure to $S s$ receiving only 20 trials. Again, schedule and the Schedule by $T$ rials interaction were not significant $(F=$ .62 and $1.51, \mathrm{df}=1 / 44$, respectively). The total speed analysis revealed nonsignificant differences for both schedule and trials $(F=3.29$ and $3.06, \mathrm{df}=1 / 44$, $\mathrm{p}>.05$, in both cases), and also the interaction of Schedule by Trials $(F=1.69, \mathrm{df}=1 / 44)$.

In general, the data indicate that the partial reinforcement acquisition effect (PRAE), where partially reinforced Ss run faster than continuously reinforced Ss 
(Brown \& Farber, 1968), occurred in the start section of the runway and not in the run section or the goal section. Absolute number of acquisition trials influenced goal speed. with faster speeds being due to a greater number of acquisition trials. Number of acquisition trials did not significantly effect run speeds or start speeds.

\section{Extinction}

All of the performance measures indicate a superiority of the CRF-PRF condition over the PRF condition. Unfortunately, acquisition differences may account for the extinction differences in the goal speed measure. It is clear, however, that the run speed measure does not involve this possible source of contamination, since none of the main effects nor the interaction was statistically significant in acquisition (Point " $A$ " in Fig. 1), and we will concentrate on this data. The analysis of run speeds revealed a highly significant effect due to schedule $(F=$ 97.84, $\mathrm{df}=1 / 44, \mathrm{p}<.001$ ) and a significant acquisition trials effect $(F=11.42, \mathrm{df}=1 / 44, \mathrm{p}<.01)$. Of most importance was the significant Schedule by Acquisition Trials interaction $(F=9.13, \mathrm{df}=1 / 44, \mathrm{p}<.01)$. These data show that both partial reinforcement and increasing acquisition trials produce greater resistance to extinction. The result of most theoretical interest was that the combined effect of CRF followed by PRF produced greater resistance to extinction than PRF by itself $(\mathrm{p}<.01)$, and the comparison of Groups CRF-20 and CRF-40 was not significant ( $p>.05$ ). Of course, the main effect of extinction days was highly significant ( $F$ $=104.50, \mathrm{df}=5 / 220, \mathrm{p}<.001)$, but more important was the significant triple interaction of Schedule by Acquisition Trials by Extinction Days $(F=2.25$, df $=$ $5 / 220, p<.05)$. This triple interaction reflects the divergence of Groups CRF-PRF and PRF, with the former showing greater resistance to extinction across trials, although both groups start at similar levels (see Fig. 1).

\section{DISCUSSION}

The data support the notion that the expectancy of reward on nonreward acquisition trials is a determinant of the PREE. The expectancy of reward was presumably established by giving CRF trials prior to PRF, and this procedure resulted in greater resistance to extinction than PRF training alone. Furthermore, the schedules of reward and nonreward events were exactly the same for the two groups receiving the PRF training, and thus differential sequential variables (Capaldi, 1967) cannot account for the extinction differences without the addition of the notion that $S^{\mathrm{N}}$ may include frustrative components. These results would seem to be most consistent with the notion that frustration is important in determining the degree of the observed PREE.

Although the present data support the hypothesis that establishing the expectancy of reward prior to partial reinforcement results in greater resistance to extinction, it is equally clear that the expectancy of reward on nonreward trials in a PRF schedule is not a necessary condition for the existence of a PREE (Spear, Hill, \& O'Sullivan, 1965). Small-trial experiments have also shown that nonreward followed by rewarded trials results in a PREE when the nonreward trials were not preceded by rewarded ones, precluding the possibility of $\mathrm{I}_{\mathrm{f}}$ being elicited on the nonreward trials (Capaldi \& Waters, 1970; Capaldi, Ziff, \& Godbout, 1970). Thus, the expectancy of reward on nonreward PRF trials does affect the magnitude of the PREE, but does not, by itself, determine the existence of the PREE.

Finally, these data are completely contrary to predictions made by stimulus analyzer theory (Sutherland \& Mackintosh, 1971) and would seem to lend some support to the previously stated criticisms of data supporting a stimulus analyzer account of the PREE (Sutherland et al, 1965). Indeed, Theios and McGinnis (1967) came to a similar conclusion with respect to differences in terminal acquisition speeds accounting for differences in extinction performance.

At least two other experiments exist which might be considered as conflicting with the present findings (Hothersall, 1966; Leung \& Jensen, 1966). In one of these experiments an operant procedure (using a VR 4 as the PRF schedule) was used (Hothersall, 1966). These data indicated that CRF prior to PRF reduced resistance to extinction, but no CRF-only controls were included to assess the influence of differing numbers of trials. In addition, response rate varied in acquisition as a function of the amount of prior CRF training. In other words, beginning immediately with the PRF schedule resulted in slower rates of response, at least in the earlier parts of acquisition. In the operant situation, rate of response might be thought of as analogous to intertrial interval in the discrete-trials procedure. It has been shown that extinction performance is affected by the combination of intertrial interval in acquisition and extinction (shifts from acquisition to extinction resulting in a decrement in resistance to extinction, Capaldi \& Minkoff, 1966). Thus, in a procedure like the free operant where the interval between successive responses is not controlled by the $E$, it is difficult to attribute the extinction effects to the occurrence of preceding CRF trials vs some other explanation such as intertrial interval (or "interresponse interval"). Leung and Jensen (1966) did use a discrete-trial (runway) procedure and also found that resistance to extinction decreased with CRF training coming prior to PRF training. A number of procedural peculiarities may limit the generality of their data. They administered 30 trials per day, and their CRF.PRF groups had 180 trials (6 days) of CRF followed by only 30 trials of PRF training ( 1 day), followed by extinction. It is not implausible that the relationship between the number of CRF and PRF trials given in that 
order may be a critical determiner of subsequent resistance to extinction. Indeed. Traupmann and Wong (cited in Amsel, 1972) have shown that 16 CRF trials preceding 32 PRF trials result in greater persistence on later extinction trials than do $64 \mathrm{CRF}$ trials preceding 32 PRF trials.

\section{REFERENCES}

Amsel, A. Partial reinforcement effects on vigor and persistence. In K. W. Spence and J. T. Spence (Eds.). The psychology of learning and motivation. Vol. 1. New York: Academic Press. 1967.

Amsel, A. Inhibition and mediation in classical, Pavlovian and instrumental conditioning. In R. Boakes and S. Halliday (Eds.), Inhibition and learning. London: Academic Press, 1972.

Brown, J. S., \& Farber, I. E. Secondary motivational systems. Annual Review of Psychology, 1968, 19, 99-134.

Capaldi, E. J. Partial reinforcement: An hypothesis of sequential effects. Psychological Review, 1966, 73, 459-477.

Capaldi, E. J. A sequential hypothesis of instrumental learning. In K. W. Spence and J. T. Spence (Eds.), The psychology of learning and motivation. Vol. 1. New York: Academic Press, 1967.

Capaldi, E. J., Berg. R. F., \& Sparling, D. D. Trial spacing and emotionality in the rat. Journal of Comparative \& Physiological Psychology, 1971, 76, 290-299.
Capaldi, E. J., \& Minkoff, R. Change in the stimulus produced by nonreward as a function of time. Psychonomic Science. 1966, 6. 321-322.

Capaldi. E. J., \& Waters, R. W. Conditioning and non-conditioning interpretations of small-trial phenomena. Journal of Experimental Psychology, 1970, 84, 518-522.

Capaldi. E. J., Ziff, D. R., \& Godbout, R. C. Extinction and the necessity or non-necessity of anticipating reward on nonrewarded trials. Psychonomic Science, 1970, 18, 61-63.

Hothersall, D. Resistance to extinction when continuous reinforcement is followed by partial reinforcement. Journal of Experimental Psychology, 1966, 72, 109-112.

Leung, C. M., \& Jensen, G. D. Shifts in percentage of reinforcement viewed as changes in incentive. Journal of Experimental Psychology, 1968, 76, 291-296.

Spear. N. E., Hill, W. F., \& O'Sullivan, D. J. Acquisition and extinction after initial trials without reward. Journal of Experimental Psychology, 1965, 69, 25-29.

Sutherland, N. S., Mackintosh, N. J. Mechanisms of animal discrimination learning. New York: Academic Press, 1971.

Sutherland, N. S., Mackintosh, N. J., \& Wolfe, J. B. Extinction as a function of the order of partial and consistent reinforcement. Journal of Experimental Psychology. 1965, 69, 56-59.

Theios, J., \& McGinnis. R. W. Partial reinforcement before and after continuous reinforcement. Journal of Experimental Psychology, 1967, 73, 479-481.

(Received for publication September 11, 1972; revision received November 29, 1972.) 